$$
\text { Special Articles }
$$

\title{
CLINICAL PROBLEMS WITH THE PERFORMANCE OF EUTHANASIA AND PHYSICIAN-ASSISTED SUICIDE IN THE NETHERLANDS
}

\author{
Johanna H. Groenewoud, M.D., Agnes van der Heide, M.D., Ph.D., Bregje D. Onwuteaka-Philipsen, Ph.D., \\ Dick L. Willems, M.D., Ph.D., Paul J. van der MaAs, M.D., Ph.D., ANd GerRit van der Wal, M.D., Ph.D.
}

\begin{abstract}
Background and Methods The characteristics and frequency of clinical problems with the performance of euthanasia and physician-assisted suicide are uncertain. We analyzed data from two studies of euthanasia and physician-assisted suicide in the Netherlands (one conducted in 1990 and 1991 and the other in 1995 and 1996), with a total of 649 cases. We categorized clinical problems as technical problems, such as difficulty inserting an intravenous line; complications, such as myoclonus or vomiting; or problems with completion, such as a longer-than-expected interval between the administration of medications and death.

Results In 114 cases, the physician's intention was to provide assistance with suicide, and in 535 , the intention was to perform euthanasia. Problems of any type were more frequent in cases of assisted suicide than in cases of euthanasia. Complications occurred in 7 percent of cases of assisted suicide, and problems with completion (a longer-than-expected time to death, failure to induce coma, or induction of coma followed by awakening of the patient) occurred in 16 percent of the cases; complications and problems with completion occurred in 3 percent and 6 percent of cases of euthanasia, respectively. The physician decided to administer a lethal medication in 21 of the cases of assisted suicide (18 percent), which thus became cases of euthanasia. The reasons for this decision included problems with completion (in 12 cases) and the inability of the patient to take all the medications (in 5).
\end{abstract}

Conclusions There may be clinical problems with the performance of euthanasia and physician-assisted suicide. In the Netherlands, physicians who intend to provide assistance with suicide sometimes end up administering a lethal medication themselves because of the patient's inability to take the medication or because of problems with the completion of physician-assisted suicide. (N Engl J Med 2000;342: 551-6.)

(C2000, Massachusetts Medical Society.
A LTHOUGH euthanasia and physicianassisted suicide are illegal in most countries, they are performed in several parts of the world. ${ }^{1-9}$ Oregon has made physician-assisted suicide legal under specified conditions. ${ }^{10}$ In the Netherlands, a physician who performs euthanasia or provides assistance with suicide will not be prosecuted if the act has been carried out under strict conditions, which have been formulated by the courts and the medical profession. ${ }^{11}$ One of these conditions is that euthanasia or assistance with suicide must be carried out in a professionally responsible way. In 1987, the Royal Dutch Association of Pharmacy issued guidelines on the use and preparation of drugs for euthanasia. The guidelines were revised on the basis of doctors' experiences in 1994 and 1998.12,13

The incidence of physician-assisted suicide and euthanasia and attitudes toward these practices have been studied extensively, but the few reports on the clinical aspects of these practices are based on limited data or small numbers of cases. ${ }^{14-18}$ We performed a study to determine whether there are problems with the clinical aspects of euthanasia and physician-assisted suicide as reported by the physicians involved, including complications and problems with completion, such as a prolonged interval between the administration of medications and the patient's death.

\section{METHODS}

\section{Study Design}

In 1990 and 1991 and in 1995 and 1996, we performed two studies of euthanasia, physician-assisted suicide, and other medical practices involving the end of life in the Netherlands. Detailed information about the design of these studies has been reported elsewhere.1,19,20 In three parts of the studies, detailed information on the clinical aspects of euthanasia and physician-assisted suicide was collected.

In 1990 and 1991, we interviewed a stratified random sample of 405 physicians that included 152 general practitioners, 50

From the Department of Public Health, Erasmus University, Rotterdam (J.H.G., A.H., P.J.M.); and the Institute for Research in Extramural Medicine and the Department of Social Medicine, Vrije Universiteit, Amsterdam (B.D.O.-P., D.L.W., G.W.) - both in the Netherlands. Address reprint requests to Dr. Groenewoud at the Department of Public Health, Erasmus University, Rotterdam, P.O. Box 1738, 3000 DR Rotterdam, the Netherlands, or at groenewoud@mgz.fgg.eur.nl. 
nursing home physicians, and 203 physicians in the specialties of cardiology, surgery, internal medicine, pulmonology, and neurology. Nine percent of eligible physicians declined to take part in the study. The interviews were based on an extensive questionnaire and lasted an average of 2.5 hours. Respondents were asked whether they had ever performed euthanasia or provided assistance with suicide. If the answer was yes, more detailed questions were asked about the most recent case. Some of the questions were about technical problems, complications, and the length of the interval between the administration of medications and death.

In 1995 and 1996, we replicated the earlier interview study. We interviewed a randomized stratified sample of 405 physicians, including 124 general practitioners, 74 nursing home physicians, and 207 physicians in the specialties noted above. Eleven percent of eligible physicians declined to take part in the study. The questionnaire was virtually identical to the one used in the 1990-1991 study.

In 1995 and 1996, we also interviewed a random sample of 147 physicians who had reported a case of physician-assisted suicide or euthanasia for judicial review by the public prosecutor between August 1, 1994, and February 1, 1995. Ten percent of eligible physicians declined to be interviewed. We asked the physicians questions about the reported case and the most recent unreported case (if any). In addition, we interviewed 63 of 64 eligible physicians who had been involved in cases of physician-assisted suicide or euthanasia discussed in the Assembly of Prosecutors General between January 1, 1991, and July 1, 1995. One physician declined to be interviewed. The questionnaire was similar to the one used in the 1990-1991 and 1995-1996 interview studies.

The protocol for the studies was reviewed and approved by a special committee of the Dutch Ministry of Health, Welfare, and Sports and the Dutch Ministry of Justice. It was also approved by the Royal Dutch Medical Association.

To obtain data from a sufficiently large number of cases, we combined all cases of euthanasia and physician-assisted suicide for which information on clinical problems was available. There were 649 such cases: 185 from the 1990-1991 interview study, 194 from the 1995-1996 interview study, and 270 from the 19951996 reported-cases study. These cases were divided into two groups according to whether the physician's intention had been to provide assistance with suicide or to perform euthanasia. Cases in which all the lethal drugs were administered by the patient were assigned to the assisted-suicide group, as were cases in which the last drug was administered by another person, although the intention had been that the patient would administer all the drugs. Cases in which someone other than the patient administered at least one of the lethal drugs at the patient's explicit request were assigned to the euthanasia group.

The data we used did not represent a random sample of cases, since we combined cases from different (stratified) samples and asked physicians about only the most recent case. We performed three analyses to assess the degree to which our data were representative of all cases of euthanasia or assisted suicide in the Netherlands. We compared the prevalence of technical problems, complications, and problems with completion between samples and according to the type of practice. We also analyzed the probability of a problem according to the number of cases of physicianassisted suicide or euthanasia that physicians had been involved in during the two years before the interview. Finally, we repeated all our analyses with only the data from the 1990-1991 interview study and the 1995-1996 interview study, which were both based on representative samples. The prevalence of technical problems, complications, and problems with completion was virtually identical for all samples and for all types of practice, and the likelihood of a problem was not related to the physician's prior experience with physician-assisted suicide or euthanasia. Therefore, we report the results for the overall samples.

Table 1. Characteristics of the Cases of Euthanasia and Physician-Assisted Suicide.

\begin{tabular}{|c|c|c|c|c|}
\hline Characteristic & $\begin{array}{c}\text { 1990-1991 } \\
\text { INTERVIEW } \\
\text { STUDY } \\
\text { (N=185) }\end{array}$ & $\begin{array}{c}1995-1996 \\
\text { INTERVIEW } \\
\text { STUDY } \\
\text { (N=194) }\end{array}$ & $\begin{array}{l}1995-1996 \\
\text { REPORTED- } \\
\text { CASES STUDY } \\
(\mathrm{N}=270)\end{array}$ & $\begin{array}{c}\text { TotAL } \\
\text { (N=649) }\end{array}$ \\
\hline \multicolumn{5}{|l|}{ Patients } \\
\hline $\operatorname{Men}(\%)^{*}$ & 51 & 59 & 54 & 55 \\
\hline \multicolumn{5}{|l|}{ Age $(\mathrm{yr}) \dagger$} \\
\hline Mean $\pm S D$ & $62.3 \pm 14.4$ & $62.6 \pm 13.8$ & $65.9 \pm 14.9$ & $63.9 \pm 14.5$ \\
\hline Range & $23-91$ & $25-91$ & $21-96$ & $21-96$ \\
\hline Diagnosis of cancer (\%)‡ & 78 & 82 & 68 & 75 \\
\hline \multicolumn{5}{|l|}{ Type of physician (\%) } \\
\hline General practitioner & 51 & 52 & 60 & 55 \\
\hline Specialist & 46 & 40 & 34 & 39 \\
\hline Nursing home physician & 3 & 8 & 6 & 6 \\
\hline \multicolumn{5}{|l|}{ Intended intervention $(\%)$} \\
\hline Euthanasia & 86 & 79 & 83 & 82 \\
\hline Physician-assisted suicide & 14 & 21 & 17 & 18 \\
\hline \multicolumn{5}{|l|}{ Year of death $(\%) \$$} \\
\hline 1987 or earlier & 38 & 13 & 8 & 18 \\
\hline $1988-1994$ & 62 & 54 & 60 & 59 \\
\hline 1995 or later & - & 34 & 33 & 23 \\
\hline
\end{tabular}

*Data were missing for one case in the 1995-1996 interview study and three cases in the reportedcases study.

†Data were missing for three cases in the 1995-1996 interview study and three cases in the re ported-cases study.

$\ddagger$ Data were missing for four cases in the 1995-1996 interview study and three cases in the reported-cases study.

\$Data were missing for 4 cases in the 1995-1996 interview study and 12 cases in the reported cases study. Because of rounding, percentages do not all total 100 
We categorized clinical problems as technical problems, such as difficulty inserting an intravenous line; complications, such as spasm, myoclonus, nausea, or vomiting; and problems with completion, such as a longer-than-expected time to death or failure to induce coma. If more than one type of medication was administered, the combination of drugs was classified according to the drug with the greatest potential for causing death. Neuromuscular relaxants and potassium chloride were considered to have the greatest lethal potential, followed by barbiturates, and then opioids. Thus, for example, if a barbiturate and a neuromuscular relaxant had been administered, the medication was classified as a neuromuscular relaxant, and if a barbiturate and an opioid had been administered, the medication was classified as a barbiturate.

\section{Statistical Analysis}

The chi-square test was used for comparisons of categorical variables. Two-sided $\mathrm{P}$ values of less than 0.05 were considered to indicate statistical significance. All statistical analyses were performed with SPSS software for Windows, version 7.5 (SPSS, Chicago).

\section{RESULTS}

The characteristics of the 649 cases of euthanasia and assisted suicide are shown in Table l. Fifty-five percent of the patients were men, and the mean age was 63.9 years (range, 21 to 96 ). Seventy-five percent of the patients had cancer. In 535 cases (82 percent), the physician intended to perform euthanasia, and in 114 cases ( 18 percent), the intention was to provide assistance with suicide.

\section{Medications}

In 367 of the 535 cases in which euthanasia was intended (69 percent), a neuromuscular relaxant was given (Table 2), in most cases after the administration of a barbiturate to induce coma. In 10 percent of the euthanasia cases, a barbiturate was the only or the most potent lethal drug administered; in 13 percent, an opioid was the only or most potent lethal drug administered. Potassium chloride was administered in 2 percent of the euthanasia cases. In 485 cases of euthanasia (91 percent), a physician administered all or some of the medications. In 29 cases (5 percent), a physician did not administer any of the drugs: a nurse administered the drugs in 23 cases, and another person (generally a family member) did so in 6 cases. In 384 cases of euthanasia $(72$ percent), the physician who completed the interview was present continuously from the time the first drug was administered until the patient's death. In 10 cases ( 2 percent), the respondent was not present at all; instead, a colleague or a nurse administered the medication.

In the group of 114 cases in which the intention was to provide assistance with suicide, a barbiturate was used in 81 cases ( 71 percent); in 9 cases ( 8 percent), an opioid was used. In 14 percent of the cases, a neuromuscular relaxant was administered after a barbiturate. In 85 cases ( 75 percent), the patient took the drug (or drugs) without help. In 5 cases, the physician or a relative helped the patient take an oral drug; in 19 other cases, the physician administered a sec-
Table 2. Medication Use during Euthanasia and PhysicianAssisted Suicide and Presence or Absence of the Physician WhO WAS INTERVIEWED.

\begin{tabular}{|c|c|c|}
\hline \multirow[t]{2}{*}{ VARIABLE } & $\begin{array}{l}\text { EUTHANASIA } \\
\text { INTENDED } \\
(\mathrm{N}=535)\end{array}$ & $\begin{array}{l}\text { Assisted SuICIDE } \\
\text { INTENDED } \\
\text { (N=114) }\end{array}$ \\
\hline & \multicolumn{2}{|c|}{ no. of cases $(\%)$} \\
\hline \multicolumn{3}{|l|}{ Medications* } \\
\hline Neuromuscular relaxant $\dagger$ & $367(69)$ & $16(14)$ \\
\hline Potassium chloride & $10(2)$ & - \\
\hline Barbiturate & $56(10)$ & $81(71)$ \\
\hline Opioid & $70(13)$ & $9(8)$ \\
\hline Other drugs or drug combinations & $19(4) \ddagger$ & $3(3) \mathfrak{S}$ \\
\hline Unknown & $13(2)$ & $5(4)$ \\
\hline \multicolumn{3}{|l|}{ Person who administered drugs } \\
\hline Physician & $485(91)$ & $21(18)$ \\
\hline Nurse & $23(4)$ & - \\
\hline Person other than physician or nurse & $6(1)$ & $3(3)$ \\
\hline Patient only & - & $85(75)$ \\
\hline Unknown & $21(4)$ & $5(4)$ \\
\hline \multicolumn{3}{|l|}{ Presence or absence of physician } \\
\hline Continuously present & $384(72)$ & $59(52)$ \\
\hline Present at intervals & $61(11)$ & $18(16)$ \\
\hline Present after being called & $39(7)$ & $20(18)$ \\
\hline Absent & $10(2)$ & $11(10)$ \\
\hline Unknown & $41(8)$ & $6(5)$ \\
\hline
\end{tabular}

*For a description of how medications were classified, see the Methods section.

†In seven cases, potassium chloride was also administered.

$\ddagger$ In eight cases, insulin was administered.

\$Insulin was administered with a barbiturate in one case, orphenadrine was administered in one case, and an unspecified combination of drugs was administered in one case.

IThe patient may also have administered one or more drugs.

ond or third drug parenterally because of complications or a perceived lack of effect of the first drug. The physician who completed the interview was continuously present in 52 percent of cases of physicianassisted suicide $(\mathrm{P}<0.001$ for the comparison with cases of euthanasia).

\section{Clinical Problems}

Table 3 shows the frequency of the clinical problems that occurred. Technical problems occurred in 35 cases ( 5 percent), complications in 24 cases ( 4 percent), and problems with completion in 44 cases (7 percent). In 10 cases, more than one type of problem occurred. Assisted suicide was more frequently associated with each type of problem than was euthanasia $(\mathrm{P}=0.03, \mathrm{P}=0.03$, and $\mathrm{P}=0.001$, respectively). General practitioners and nursing home physicians were more likely than specialists to report technical problems $(\mathrm{P}<0.001)$ and problems with completion $(\mathrm{P}=0.04)$. Oral or rectal administration of medications was more likely than parenteral administration to be associated with technical problems $(\mathrm{P}=0.003)$ and problems with completion $(\mathrm{P}<0.001)$. 
Table 3. Clinical Problems Associated with Euthanasia and Physician-Assisted Suicide.*

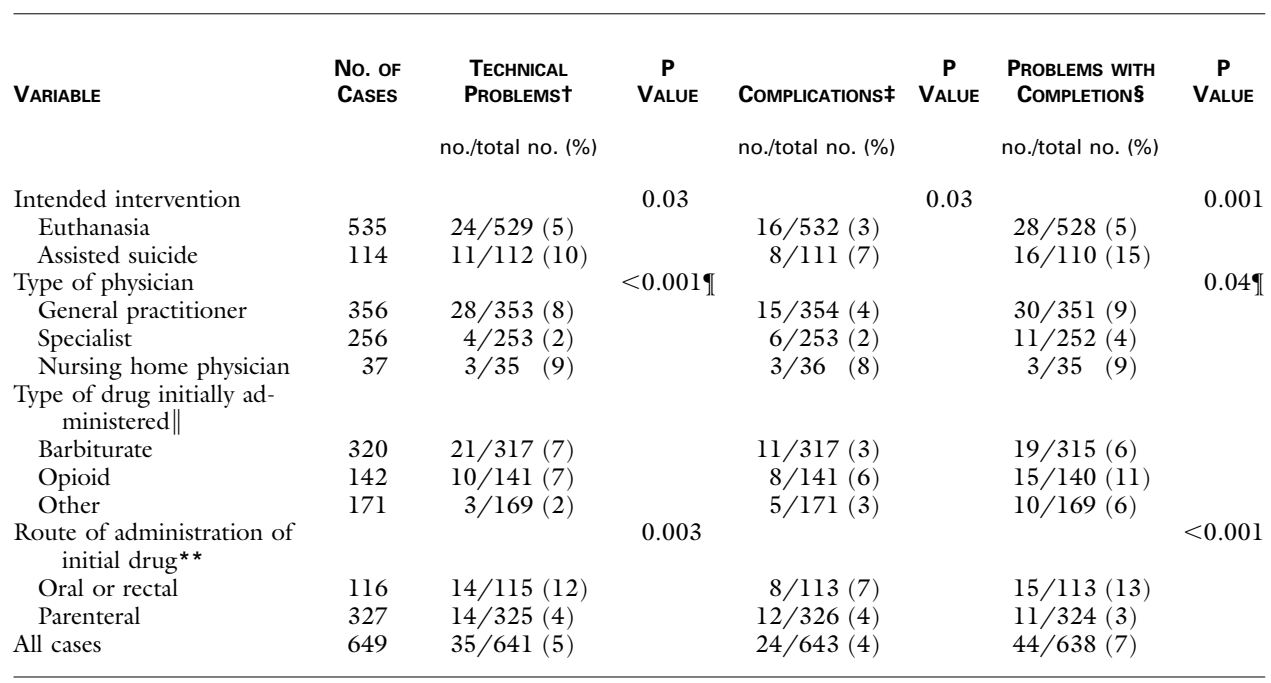

*In 10 cases, more than one type of problem occurred.

†Data were not available for eight cases.

$\ddagger$ Data were not available for six cases.

\$Data were not available for 11 cases.

IThe $\mathrm{P}$ value is for the comparison of general practitioners and nursing home physicians with specialists.

|| The type of drug was not specified in 16 cases.

**In the 1990-1991 interview study, the route of administration was not determined; the 185 cases in that study were therefore excluded from this analysis. In addition, data were not available for 21 cases in the other two studies; these cases have also been excluded from the analysis.

Specific information about the reported problems is provided in Table 4 . The most common technical problems were difficulty finding a vein in which to inject the drug and difficulty administering an oral medication. The most frequently mentioned complications were spasm or myoclonus and nausea or vomiting. The most common problems with completion were a longer-than-expected interval between the administration of medications and death and failure to induce a comatose state. Table 5 shows the interval between the administration of the medication (or the first medication, if there was more than one) and the patient's death, as well as the physician's assessment of whether the interval was shorter than expected, longer than expected, or as expected.

\section{Intervention of Physician in Cases of Assisted Suicide}

In 21 of the cases in which the intention had been to provide assistance with suicide, the physician administered the lethal drug. In 12 of these cases, a problem with completion was mentioned as the reason for the physician's intervention: the interval between the administration of medication and the occurrence of coma or death was too long (in 9 cases), the patient did not become comatose after taking the first drug (in 1), or the patient awoke from coma (in
2 ). In five other cases, the physician intervened because the patient had difficulty taking all the oral medication; for example, one patient vomited after taking the first medication, and one patient fell asleep before taking all the medication. In four cases, no specific reason for the physician's intervention was given.

\section{DISCUSSION}

We found that there were sometimes clinical problems with the performance of physician-assisted suicide and euthanasia. The problems reported by physicians frequently concerned a longer-than-expected interval between the administration of the lethal drug (or the first drug, if more than one was administered) and the patient's death. In general, problems were more frequently reported in cases of assisted suicide than in cases of euthanasia. The responsible physician decided to administer the lethal medication in 21 of 114 cases in which the original intention had been only to provide assistance with suicide. In most of these cases, the patient did not die as soon as expected or awoke from coma, and the physician felt compelled to administer a lethal injection because of the anticipated failure of the assisted suicide. In some cases, the physician administered a lethal injection because the patient had difficulty swallowing the oral 
Table 4. Specific Technical Problems, Complications, and Problems With COMPLetion.

\begin{tabular}{|c|c|c|}
\hline \multirow[t]{2}{*}{ Specific Problem } & $\begin{array}{l}\text { EUTHANASIA } \\
\text { INTENDED } \\
\text { ( } N=535)\end{array}$ & $\begin{array}{l}\text { Assisted SuICIDE } \\
\text { INTENDED } \\
(\mathbf{N}=114)\end{array}$ \\
\hline & \multicolumn{2}{|c|}{ no. of cases } \\
\hline \multicolumn{3}{|l|}{ Technical problems } \\
\hline $\begin{array}{l}\text { Difficulty finding vein in which to } \\
\text { inject drug }\end{array}$ & $10^{*}$ & $1 \dagger$ \\
\hline Problem with the intravenous catheter & 4 & 0 \\
\hline Difficulty administering oral drug & 4 & 7 \\
\hline Other $\neq$ & 3 & 3 \\
\hline Not specified & 3 & 0 \\
\hline \multicolumn{3}{|l|}{ Complications $\$$} \\
\hline Spasm or myoclonus & 6 & 1 \\
\hline Cyanosis & 4 & 1 \\
\hline Nausea or vomiting & 2 & 4 \\
\hline Other & $7 \mathbb{I}$ & $4 \|$ \\
\hline Not specified & 1 & 0 \\
\hline \multicolumn{3}{|l|}{ Problems with completion } \\
\hline $\begin{array}{l}\text { Time to death was longer than ex- } \\
\text { pected or patient did not become } \\
\text { comatose }\end{array}$ & 23 & 14 \\
\hline Patient awoke from coma & 5 & 2 \\
\hline
\end{tabular}

*In one case, intravenous injection was difficult because of lymphedema. In two other cases, the physician finally administered the drug intramuscularly.

†Fluid injected into a vein flowed back out of the vein at the injection site. $\ddagger$ Other problems included inappropriate equipment and drugs that were unpleasant to swallow or that irritated the throat.

$\$$ In six cases, two complications were reported.

IIn one case, the patient's eyes remained open, and in another case, the patient sat up. Other complications included tachycardia, excessive production of mucus, hiccups, perspiration, and extreme gasping.

$\|$ Other complications were a feeling of drunkenness in one case and extreme gasping in three cases.

medication, vomited after swallowing it, or became unconscious before swallowing all of it.

Two limitations of our study should be considered. First, we included all cases of euthanasia and physician-assisted suicide for which we had clinical information. These cases may not be representative of all cases of euthanasia and assisted suicide in the Netherlands. We performed several analyses to check for differences between samples or strata, which did not yield any significant differences. Second, the information was provided by the responsible physician in each case, who may have underestimated the number or seriousness of problems.

In two other Dutch studies of the clinical aspects of euthanasia and physician-assisted suicide, general practitioners and nursing home physicians reported problems in 12 percent and 7 percent of cases, respectively. ${ }^{14,15}$ In a study of physician-assisted suicide in the United States, Emanuel et al. reported that assisted suicide failed in 3 of 20 cases described by American oncologists. ${ }^{16}$ In a study in Washington State, no unsuccessful attempts at physician-assisted suicide
Table 5. Interval from the Administration of the First Drug to Death and the Physician's Assessment OF THE INTERVAL.

\begin{tabular}{|c|c|c|c|}
\hline \multirow[t]{2}{*}{ Physician's Assessment } & \multirow[t]{2}{*}{ No. of Cases (\%) } & \multicolumn{2}{|r|}{ INTERVAL* } \\
\hline & & MEDIAN & RANGE \\
\hline & & $\min$ & \\
\hline \multicolumn{4}{|l|}{ Euthanasia intended $\dagger$} \\
\hline All cases & 535 & 10 & $0.5 \mathrm{~min}-7$ days \\
\hline As expected & $449(84)$ & 10 & $0.5 \mathrm{~min}-4$ days \\
\hline Shorter than expected & $18(3)$ & 5 & $0.5 \mathrm{~min}-12 \mathrm{hr}$ \\
\hline Longer than expected & $51(10)$ & 180 & 5 min -7 days \\
\hline \multicolumn{4}{|l|}{$\begin{array}{l}\text { Physician-assisted } \\
\text { suicide intended } \ddagger\end{array}$} \\
\hline All cases & 114 & 30 & $1 \mathrm{~min}-14$ days \\
\hline As expected & $67(59)$ & 30 & $2 \min -14$ days \\
\hline Shorter than expected & $13(11)$ & 8 & $1 \mathrm{~min}-2 \mathrm{hr}$ \\
\hline Longer than expected & $22(19)$ & 180 & $45 \min -7$ days \\
\hline
\end{tabular}

*Data on the actual interval between the administration of the first drug and death were not available for 33 cases in which euthanasia was intended and for 9 in which assisted suicide was intended.

†In 10 cases, the interval differed from the expected interval but was not specified as shorter or longer; in 7 cases, the physician's assessment of the interval was not available.

$\ddagger$ In five cases, the interval differed from the expected interval but was not specified as shorter or longer; in seven cases, the physician's assessment of the interval was not available.

were reported. ${ }^{17}$ In 15 cases of physician-assisted suicide in Oregon, no complications, such as vomiting or seizures, occurred. ${ }^{18}$

Information on problems with the performance of euthanasia or physician-assisted suicide is relevant to the debate about whether to legalize these practices, for several reasons. First, such information may be helpful in cases in which the distinction between physician-assisted suicide and euthanasia is unclear. We found that in most cases in which assistance with suicide had been intended, the physician's role was confined to prescribing or supplying the drugs to be used. In 21 percent of the cases, however, the physician or another person helped the patient take one or more of the drugs. It is not clear at what point a physician's assistance with suicide becomes euthanasia. For example, how should cases be classified in which the physician pours an oral medication into the patient's mouth because the patient is unable to administer it? A judicial distinction between physician-assisted suicide and euthanasia may be complicated by such practical issues. ${ }^{21}$

Second, if physician-assisted suicide is legalized but euthanasia is not, some competent patients may not be able to end their own lives for purely physical reasons, as in the case of patients with neurologic illnesses who have problems with swallowing or using their hands and patients who are physically too weak to take all the oral medication themselves. One study 
found that general practitioners and nursing home physicians preferred euthanasia to assisted suicide because of limitations imposed by the patient's condition in 48 percent of 155 cases of euthanasia and in 78 percent of 50 cases, respectively. 22

Third, a physician who decides to assist with a patient's death should have adequate knowledge of the technical performance of euthanasia and physicianassisted suicide. In the Netherlands, one of the requirements for prudent practice concerns care in choosing doses and administering medications. ${ }^{23}$ The Royal Dutch Association of Pharmacy recognized in the 1980s that physicians and pharmacists should have at their disposal reliable information on the technical performance of euthanasia, and the association regularly updates its guidelines on the use and preparation of relevant drugs. ${ }^{12,13}$ Studies in the United States and in the Netherlands have shown that many physicians lack knowledge about the use of lethal drugs and that recommendations about which drugs to use are not always followed. 2,13,16-18,24,25

Finally, the responsible physician's presence must be considered. According to the Royal Dutch Medical Association, the physician should be present when euthanasia or physician-assisted suicide is carried out. A physician who decides not to be present (e.g., at the patient's request) should make arrangements to be available if the prescribed drugs fail to have the intended effect. ${ }^{26}$ About two thirds of both general practitioners and nursing home physicians in the Netherlands endorse the statement that a physician who provides assistance with suicide should be prepared to administer a lethal drug if the suicide attempt fails. ${ }^{27}$ To be available under such circumstances, the physician must have previously informed the patient and the patient's relatives about what to expect during the actual performance of physician-assisted suicide, including possible complications and the expected interval between the administration of the medication and death.

Decisions about physician-assisted suicide and euthanasia are difficult and emotional for all persons involved. Unexpected events can be traumatic. Professional training, empirical research, and an open debate on the practical aspects of physician-assisted suicide and euthanasia may contribute to the prevention of complications and other clinical problems.

Supported by a grant from the Dutch Ministry of Health, Welfare, and Sports and the Dutch Ministry of Justice.

We are indebted to Johannes J.M. van Delden and Loes Pijnenborg, for their contributions to the 1990-1991 study; to Ilinka Haverkate and Jacqueline M. Cuperus-Bosma, for their contributions to the 1995-1996 study; to Caspar W.N. Looman, for his statistical advice; to all the physicians who participated in the two studies; and to the interviewers.

\section{REFERENCES}

1. van der Maas PJ, van der Wal G, Haverkate I, et al. Euthanasia, physician-assisted suicide, and other medical practices involving the end of life in the Netherlands, 1990-1995. N Engl J Med 1996;335:1699-705. 2. Meier DE, Emmons C-A, Wallenstein S, Quill T, Morrison RS, Cassel CK. A national survey of physician-assisted suicide and euthanasia in the United States. N Engl J Med 1998;338:1193-201.

3. Kuhse H, Singer P, Baume P, Clark M, Rickard M. End-of-life decisions in Australian medical practice. Med J Aust 1997;166:191-6.

4. Matzo ML, Emanuel EJ. Oncology nurses' practices of assisted suicide and patient-requested euthanasia. Oncol Nurs Forum 1997;24:1725-32.

5. Emanuel EJ, Fairclough DL, Daniels ER, Clarridge BR. Euthanasia and physician-assisted suicide: attitudes and experiences of oncology patients, oncologists, and the public. Lancet 1996;347:1805-10.

6. Asch DA. The role of critical care nurses in euthanasia and assisted suicide. N Engl J Med 1996;334:1374-9.

7. Doukas DJ, Waterhouse D, Gorenflo DW, Seid J. Attitudes and behaviors on physician-assisted death: a study of Michigan oncologists. J Clin Oncol 1995;13:1055-61.

8. Baume P, O'Malley E. Euthanasia: attitudes and practices of medical practitioners. Med J Aust 1994;161:137, 140, 142-4.

9. Fried TR, Stein MD, O'Sullivan PS, Brock DW, Novack DH. Limits of patient autonomy: physician attitudes and practices regarding life-sustaining treatments and euthanasia. Arch Intern Med 1993;153:722-8.

10. Oreg. Rev. Stat. 127,800-127,897 (the Oregon Death with Dignity Act) (1994).

11. Gevers S. Euthanasia: law and practice in the Netherlands. Br Med Bull 1996;52:326-33.

12. Toepassing en bereiding van euthanatica. 's-Gravenhage, the Netherlands: Koninklijke Nederlandse Maatschappij ter bevordering der Pharmacie, 1994.

13. Wetenschappelijk Instituut Nederlandse Apothekers. Euthanaticarapport herzien. Adviezen voor de toepassing van euthanatica. Med Contact 1998;53:1366-7.

14. van der Wal G, van Eijk JTM, Leenen HJJ, Spreeuwenberg C. Het gebruik van middelen bij euthanasie en hulp bij zelfdoding in de huisartspraktijk. Ned Tijdschr Geneeskd 1992;136:1299-305.

15. Muller MT, Hertogh CMPM, van der Wal G, Ribbe MW. Medisch technische aspecten van euthanasie en hulp bij zelfdoding in de verpleeghuisgeneeskunde. Vox Hosp 1992;16:3-7.

16. Emanuel EJ, Daniels ER, Fairclough DL, Clarridge BR. The practice of euthanasia and physician-assisted suicide in the United States: adherence to proposed safeguards and effects on physicians. JAMA 1998;280: 507-13.

17. Back AL, Wallace JI, Starks HE, Pearlman RA. Physician-assisted suicide and euthanasia in Washington State: patient requests and physician responses. JAMA 1996;275:919-25.

18. Chin AE, Hedberg K, Higginson GK, Fleming DW. Legalized physician-assisted suicide in Oregon - the first year's experience. N Engl J Med 1999;340:577-83

19. Van Der Maas PJ, Van Delden JJM, Pijnenborg L, Looman CWN. Euthanasia and other medical decisions concerning the end of life. Lancet 1991;338:669-74.

20. van der Wal G, van der Maas PJ, Bosma JM, et al. Evaluation of the notification procedure for physician-assisted death in the Netherlands. N Engl J Med 1996;335:1706-11.

21. Woolfrey J. What happens now? Oregon and physician-assisted suicide. Hastings Cent Rep 1998;28(3):9-17.

22. Onwuteaka-Philipsen BD, Muller MT, van der Wal G, van Eijk JT,

Ribbe MW. Active voluntary euthanasia or physician-assisted suicide? J Am Geriatr Soc 1997;45:1208-13.

23. Legemaate J. Legal aspects of euthanasia and assisted suicide in the Netherlands, 1973-1994. Camb Q Healthcare Ethics 1995;4:112-21.

24. Drickamer MA, Lee MA, Ganzini L. Practical issues in physicianassisted suicide. Ann Intern Med 1997;126:146-51

25. Lee MA, Nelson HD, Tilden VP, Ganzini L, Schmidt TA, Tolle SW. Legalizing assisted suicide - views of physicians in Oregon. N Engl J Med 1996;334:310-5.

26. General Board RDMA. Vision on euthanasia. In: Euthanasia in the Netherlands. Utrecht, the Netherlands: Royal Dutch Medical Association, 1996

27. Onwuteaka-Philipsen BD, Muller MT, van der Wal G, van Eijk JT, Ribbe MW. Attitudes of Dutch general practitioners and nursing home physicians to active voluntary euthanasia and physician-assisted suicide. Arch Fam Med 1995;4:951-5. 